\title{
Theoretical and practical aspects regarding the implant-prosthetic rehabilitation in smoker patients - preliminary study
}

\author{
Bogdan PAVAL ${ }^{1}$, Augustin MIHAI ${ }^{1}$, Mihai BURLIBASA ${ }^{1}$, Cosmin MEDAR ${ }^{1}$, Viorel Stefan PERIEANU ${ }^{1}$, \\ Madalina Violeta PERIEANU ${ }^{1}$, Radu COSTEA ${ }^{1}$, Madalina Adriana MALITA ${ }^{1}$, \\ Raluca COSTEA ${ }^{2}$, Corina Marilena CRISTACHE ${ }^{1}$, Maria Glencora COSTACHE ${ }^{1}$, \\ Magdalena Natalia DINA ${ }^{1}$, Simion Gheorghe DUMITRU ${ }^{1}$, Irina Adriana BEURAN ${ }^{1}$, \\ Oana-Cella ANDREI ${ }^{1}$, Gabriela TANASE ${ }^{1}$ \\ 1"Carol Davila" University of Medicine and Pharmacy, Bucharest, Romania \\ ${ }^{2}$ Dental Practice, Brasov, Romania
}

\begin{abstract}
Implant-prosthetic rehabilitation (both the surgical step of inserting dental implants and also the stage of creating the implant-supported prosthetic restorations) in smokers patients poses particular problems not only for the medical team but also for the patients (and here we refer in particular to the average number of cigarettes smoked daily).

Purpose. In this paper we have attempted to present a multitude of factors both theoretical and practical, which can intervene in the implant-prosthetic rehabilitation of heavy smoker patients.

Material and method. The study was conducted between April 2018 and November 2018 by applying a questionnaire with 6 questions. The 31 subjects enrolled in the study were aged between 29 to 67 years old, specialists and/or primary doctors of general dentistry, dental prosthodontics or dental surgery.

Results and discussions. Centralized results have been processed to provide a clearer picture of the current attitude towards heavy smokers for oral rehabilitation with the implant-supported restorations.

Conclusions. The insertion of dental implants and subsequent creation of implant-supported restorations are not an interdiction for heavy smokers (up to 60 cigarettes a day) but requires the involvement of both the medical team and especially the patients in the follow-up care period to increase long-term success of dental implants and prosthetic restorations made thereon.
\end{abstract}

Keywords: heavy smoker patients, dental implants, implant-supported prosthetic restorations

\section{INTRODUCTION}

Smoking is one of the most harmful habits for the human body, which affects more or less all organs. This vicious but also extremely dam- aging habit can be associated with many local and systemic illnesses, affecting not only the quality of life of the individual smoker, but also drastically decreasing his life expectancy. Thus, in addition to affecting the structures of the oral 
cavity, smoking can be incriminated in the production of heart attack, lung cancer, pulmonary bronchitis, kidney and bladder disease, digestive and liver disorders etc. (1-6).

Cigarette smoke contains a number of harmful substances, consisting of 2 phases: a gaseous phase (containing ammonia, formaldehyde, carbon monoxide, as well as a number of about 70 carcinogenic potential products such as benzoprene and dimethylnitozamines) and a solid phase (containing nicotine tar, benzine and benzopirines) (1-6).

This nicotine tart which forms the solid phase of cigarette smoke, tar inhaled with cigarette smoke, is sticky in its condensed form and produces yellowish-brown stains on dental surfaces. Nicotine, an alkaloid compound with rapid absorption in the pulmonary circulation, quickly reaches the brain, creates dependence, increases blood pressure and produces peripheral vasoconstriction (1-6).

But, at the oral cavity, cigarette smoke is more often incriminated in the occurrence of precancerous lesions (leukoplasia, erythroplasty, keratosis), cancerous lesions (squamous cell carcinoma), periodontal disease (ischemia, scarring, periodontal system infections, periodontal pockets, gingival and alveolar retraction), peri-implantitis, halitosis, root caries, increased incidence of dental caries, alteration of taste perception etc. (1-6).

In this study, we are interested in the many aspects that may appear in implant-prosthetic rehabilitated smoker patients, namely: both after the surgical stage, the insertion of the dental implants, then during the ostoeintegration period, and subsequently in the stage after creating the implant-supported prosthetic restorations. In this sense, it is still necessary to give a very succinct explanation of the main specialty notions, which we will use in the making this article.

\section{GENERAL DATA}

Definitely, tobacco dependence is currently for classical smokers, already a chronic state. At the same time, we can even say that nicotine is found in the drug family, and the dependence induced and maintained by it requires repeated interventions, some even very expensive, especially from health point of view (nicotine addiction consists of physical dependence and psychological dependence) (1-4). In the context of this study, we talk about smokers, daily smokers not occasional smokers, patients who smoke greater than 20 and at most 60 cigarettes a day.

In dentistry, the insertion of dental implants is a surgical step, and the implant-supported prosthetic restorations are a mixed stage, comprising both clinical (implying dental office) and technical (implying dental laboratory) phases. Thus, the insertion of dental implants and subsequent creation of implant-supported restorations in smoker patients up to 60 cigarettes a day is not, from our point of view, a prohibition, but involves a set of recommendations from the medical team which must be implemented by the patients, for the success of subsequent implant-prosthetic rehabilitation. But the insertion of dental implants for patients who smoke on daily average from 60 cigarettes up, we do not recommend the use of these devices because the risk of rejection can become a certainty (7-16).

Among the harmful effects that smoking can have on dental implants and thus on implant-supported prosthetic restorations, we recall (1-6):

- In the short term, smoking slows down bone and soft tissue healing and may even call into question the tissular integration of dental implants (epithelial and bone integration);

- In the medium and long term, smoking may contribute to frequency increase of complications that occur around dental implants, which in time may even lead to implant loss and also of implant-supported prosthetic restorations, issues well evidenced by medical imaging. Among these complications, the following should be mentioned: loss of bone structures following insertion of the dental implant; increasing the incidence of peri-implantitis (peri-implantitis can be considered a localized infection, which has many aspects in common with chronic periodontal disease); influencing the success rate of bone grafts etc.;

- Smoking allows excessive accumulation of dental microbial plaques on implant-supported prosthetic restorations, in a much shorter time than normal, and the microbial bio-film can irreversibly affect the stability of the dental implants and therefore of these prosthetic works;

- Smoking greatly inhibits the effectiveness of antibiotics, as well as of antiseptics and/or other medicinal products recommended by the dental team, both imme- 
diately after implant surgery and subsequently after creating implant-supported restorations.

\section{PURPOSE OF THE STUDY}

Having as a starting point these harmful effects that smoking can produce on dental implants, as well on implant-supported restorations, but also after studying literature, to prevent lowering the success rate of dental implants and implant-supported restorations in smokers (with a daily average of up to 60 cigarettes), dentists are able to make a number of recommendations to these patients, recommendations from which we mention:

- First of all, it would be ideal for the patient to give up smoking definitively, or at least a week or two before the insertion of the dental implants and 8 weeks thereafter. From our point of view, in order to ensure medium and long term stability of dental implants and subsequently maintenance of implant-supported prosthetic restorations in the oral cavity, it is advisable to quit smoking at least 2-3 weeks before insertion dental implants.

- Secondly, in addition to the definitively give up of this vicious habit, it is recommended to remove the microbial plaque from the oral cavity, including the one that appear on the implant-supported prosthetic restorations, in order to avoid the occurrence of peri-implantitis, through rigorous hygiene provided by patients or by the prophylactic measures provided by the dental team at least 3 times a year. Practically, prevention of peri-implant diseases should be an important goal for both the physician and the patient.

Specifically, preventative care standards must be part of treatments through implant-supported prosthetic restorations and become a routine practice. Patient comfort should be considered, and can be achieved by daily appliance of oral hygiene measures (which should take into account the doctor's recommendations, depending on the particularities of dental implant treatment); At the same time, the effort of the medical team, which manages to motivate the patient for the daily appliance of the prophylactic methods, but also by the appliance of the professional hygiene measures within the follow-up period, is extremely important (1-4). But to achieve these goals, both patients (and here we refer especially to smokers) and dental practitioners need to be aware, these things being the purpose of this study.

\section{MATERIAL AND METHOD}

In the practice of dental medicine, by patient follow-up care we understand (1-4): prevention, detection, control and treatment of relapses or new diseases (for example, in our case, peri-implantitis). Follow-up care the implant-prosthetic rehabilitated patient includes the following steps (1-4):

- Updating the medical and dental history;

- Examination of soft extra- and intra- oral tissues;

- Clinical evaluation of dental implants;

- Performing control radiographs;

- Removing the microbial plaque and tartar;

- Checking for proper oral hygiene realized by the patient.

To carry out this study, a total of 31 dentists were selected with ages between 29 and 67 years old. All subjects involved in the study are specialists and/or primary doctors of general dentistry, dental prosthodontics or dental surgery. Of these 31 subjects, 22 were female (representing $70.97 \%$ ), while 9 subjects were male (representing $29.03 \%$ ) (Fig. 1). The study was conducted between April 2018 and November 2018.

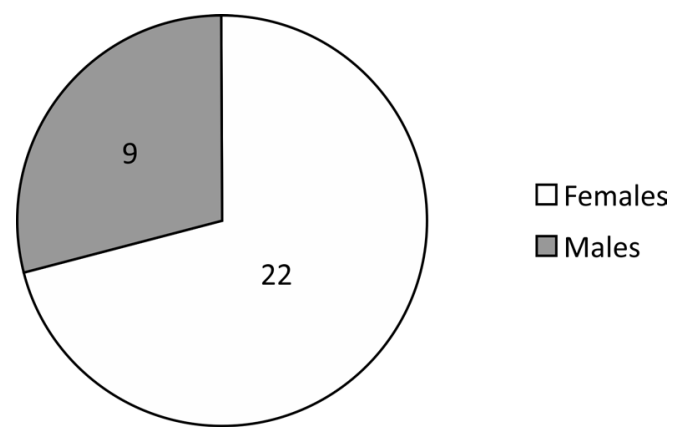

FIGURE 1. Composition of the study group

The method chosen for this study was the questionnaire. It consisted of 6 questions that were applied to the 31 subjects involved in the study, subject to anonymity. By applying this questionnaire, it was actually attempted to implement a working protocol amongst practitioners regarding the implant-prosthetic rehabilitation of smoker patients, daily smokers not occasional smokers, patients who smoked an daily average between at least 20 and at most 60 cigarettes. 
The questionnaire applied to the 31 subjects has the following composition, as well as the correct answers (from the point of view of the authors):

\section{Questionnaire}

1. Do you consider that the insertion of dental implants in smoker patients, where the daily average of smoked cigarettes exceeds 60 pieces, is: $\boldsymbol{a}$. A categorical interdiction. $\boldsymbol{b}$. Presents a reduced dose of risk, but can be countered by firm measures imposed by the dental team. c. Standard recommendation, subjected to high costs?

\section{Correct answer: $a$.}

2. For implant-prosthetic rehabilitate patients, cigarette smoke can lead: $\boldsymbol{a}$. The occurrence of acute serous pulpitis; $\boldsymbol{b}$. The occurrence of peri-implantitis; $c$. The excessive accumulation of dental microbial plaque on the implant-supported restorations; $\boldsymbol{d}$. Alterations in taste perception?

Correct answers: $b, c, d$.

3. In order to prevent lowering the success rate of dental implants and implant-supported restorations on short, medium and long-term in smokers (daily average up to 60 cigarettes), it would be ideally: $\boldsymbol{a}$. That the patient quit smoking completely; $\boldsymbol{b}$. That the patient reduces the number of cigarettes smoked daily by 20\%; . That the patient reduces the number of cigarettes smoked daily by $30 \%$ ?

\section{Correct answer: $\boldsymbol{a}$.}

4. In order to prevent the occurrence of peri-implantitis in smoker patients rehabilitated with implant-supported restorations, it is recommended to: $\boldsymbol{a}$. Definitively quit smoking; $\boldsymbol{b}$. Removing the entire dental microbial plaque from the oral cavity (including the one created on the surface of implant-supported restorations) through a rigorous hygiene provided by both the patient and the dental team; c. An appropriate prophylactic antibiotic treatment?

\section{Correct answers: $\boldsymbol{a}, \boldsymbol{b}$.}

5. Preventive care standards for implant-prosthetic rehabilitated smoker patients should be: a. An integral part of implant-supported prosthetic restorations; $\boldsymbol{b}$. Be a routine practice; $\boldsymbol{c}$. Consider patient comfort, which can be achieved by daily oral appliance of oral hygiene measures; $\boldsymbol{d}$. Take into account the efforts of the dental team, which manages to motivate the patient for the daily appliance of the prophylactic methods, but also by applying professional hygiene measures within the follow-up care period?

\section{Correct answers: $a, b, c, d$.}

6. The follow-up care of the implant-prosthetic rehabilitated patient includes the following steps: $a$. Updating the medical and dental history; $\boldsymbol{b}$. Examination of soft tissues extraoral and intraoral; c. Clinical evaluation of dental implants; d. Performing control radiographs; e. Removal of microbial plaque and tartar; $f$. Checking for a proper oral hygiene made by the patient?

Correct answers: $a, b, c, d, e, f$.

\section{RESULTS AND DISCUSSIONS}

The analysis of the answers obtained by applying the questionnaire revealed the following aspects:

Regarding the insertion of dental implants in highly smoked patients (with a daily average of more than 60 cigarettes), $67.74 \%$ of the respondents (21 subjects) responded correctly (answer $a$ ), while the remaining $32.26 \%$ respondents (10 subjects) opted for response $\boldsymbol{b}$ (Fig. 2).

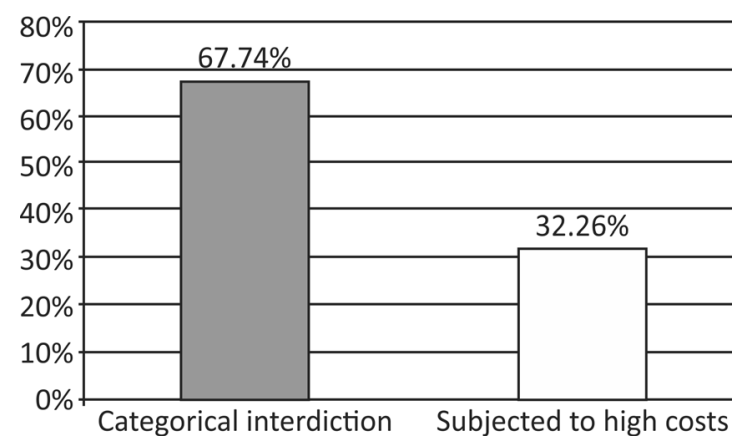

FIGURE 2. Physicians' attitude towards the insertion of implants for heavy smoker patients

The second question related to the effects of cigarette smoke offered the following responses from the subjects involved in the study: 27 of them (representing $87.10 \%$ ) responded correctly (answers $\boldsymbol{b}, \boldsymbol{c}$ and $\boldsymbol{d}$ ) while only 4 subjects included beside correct answers the answer variant $\boldsymbol{a}$ (Fig. 3).

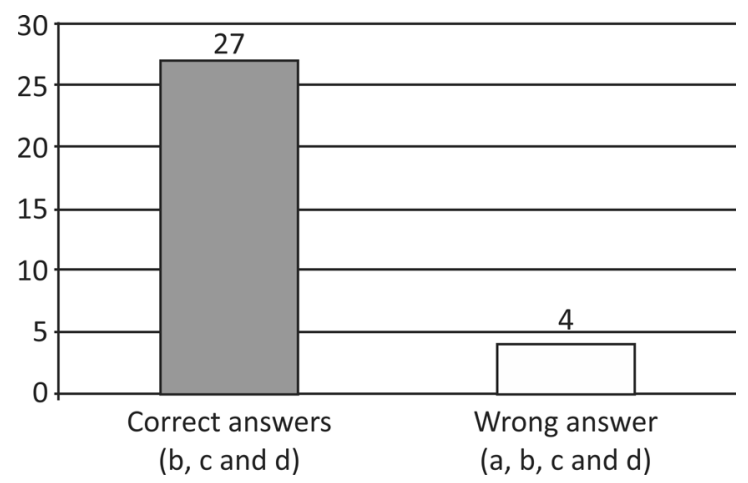

FIGURE 3. Effects of cigarette smoke on implantprosthetic rehabilitated patients 
Concerning the directions that patients should follow in order to prevent lowering the success rate of dental implants, the great majority of doctors involved in the study $(77.42 \%)$ considered as a viable option to definitively quit smoking (answer $\boldsymbol{a}$ ), while only 7 doctors (22.58\%) considered viable the $30 \%$ reduction of cigarette consumption (Fig. 4).

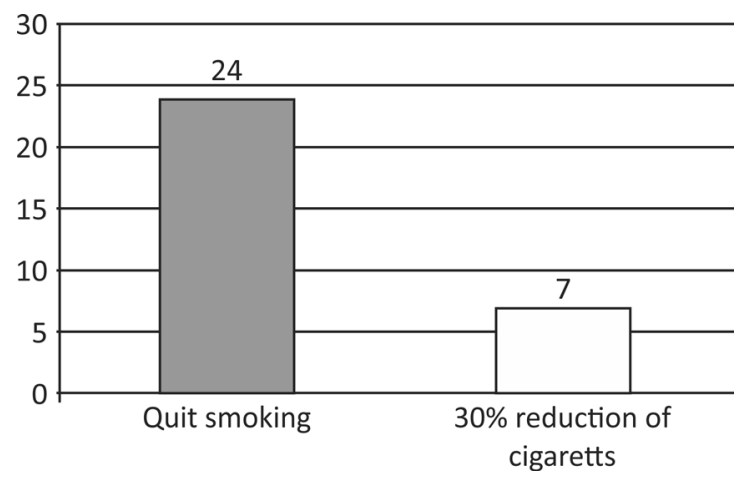

FIGURE 4. Improve the success rate of dental implants by changing the number of cigarettes smoked per day

Among the ways to prevent peri-implantitis in smoking patients, 11 practitioners chose all the answer options (a partially wrong solution) while 20 of the practitioners (representing $64.52 \%$ ) chose the correct options of response $a$ and $\boldsymbol{b}$ (Fig. 5).

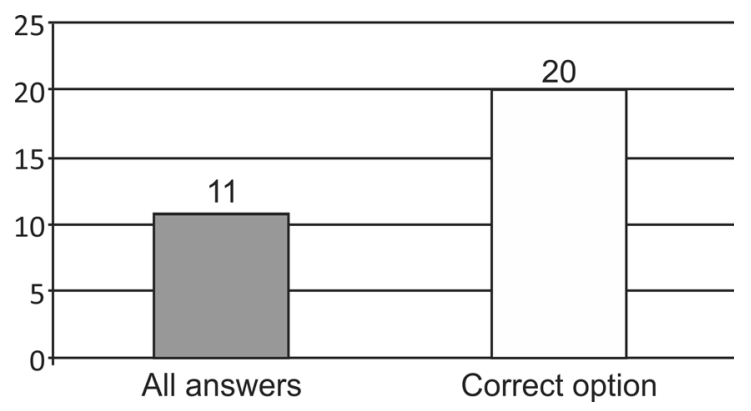

FIGURE 5. Ways to prevent peri-implantitis for smoker patients.

For the last two questions of this study related to preventive care standards and follow-up care of implant-prosthetic rehabilitated smoker patients, all physicians participating in this study provided the correct answers $(\boldsymbol{a}, \boldsymbol{b}, \boldsymbol{c}$ and $\boldsymbol{d}$ for question $5, a, b, c, d, e$ and $f$ for question 6 ), which shows a correct and perspective thinking of the medical staff involved in this process.

\section{CONCLUSIONS}

After analyzing the answers for the 6 questions, we can conclude several extremely interesting aspects, as follows:
The insertion of dental implants and subsequent creation of implant-supported restorations in smokers up to 60 cigarettes a day is not an interdiction, but involves a set of recommendations from the medical team that patients need to put into practice: definitively quit smoking followed by a proper hygiene of the oral cavity, made by the patient and professional by the dental team. On the other hand, insertion of dental implants is not recommended in patients who smoke on average daily more than 60 cigarettes.

In smokers, including implant-prosthetic rehabilitated ones, cigarette smoke can be incriminated in precancerous lesions (leukoplasia, erythroplasia, keratosis), cancerous lesions (squamous cell carcinoma), periodontal disease (ischemia, accumulations plaque and tartar, infections of periodontal system, periodontal pockets, gingival and alveolar bone retraction), peri-implantitis, halitosis, root caries, increased incidence of dental caries, alteration of taste perception etc.

In order to have medium- and long-term success of implant-prosthetic rehabilitation in smoker patients, it is recommended to quit this vicious habit, which is smoking.

Microbial dental plaque (in fact, microbial bio-film in the oral cavity) and any inflammatory processes in this region may lead to unfavorable conditions that compromise the success of implant-prosthetic treatment not only in smoker patients but in any patient. The tissues surrounding the implant are considered to be at high risk of inflammation occurrence in the presence of the dental microbial plaque.

If at first, the key to success in implant-prosthetic rehabilitation was considered the surgical step of insertion of dental implants, later attention was directed to achieving prosthetic treatment. Recently, prophylactic treatment (with the main two segments: professional care and personal hygiene) is considered to be the key factor, which ensures the medium- and longterm success in maintaining implant-prosthetic restorations in both smoker and non-smoker patients.

The occurrence of peri-implantitis is seen more frequently among smoker than non-smoker patients. The effects of smoking are patient-dependent, but associated factors such as past history of the periodontal disease, oral personal hygiene, type of maxillary / mandibular arch, type of implant surface treatment etc. must be taken into account. 
Follow-up care is a mandatory measure for implant-prosthetic rehabilitated patients, both for non-smokers, but especially for smokers.

\section{ACKNOWLEDGEMENT}

In this article, all the authors have equal contributions with the first author.

Conflict of interest: none declared

Financial support: none declared

\section{REFERENCES}

1. Excellence, Dental. Influența fumanutului asupra unui implant dentar. www. dentalexcellence.ro. [Online] [Cited: Dec 16, 2018.] https://www.dentalexcellence.ro/ influenta-fumatului-asupra-unui-implantdentar/.

2. E Stanciu. Efectele fumatului asupra implantului dentar. www.romedic.ro. [Online] [Cited: Dec 19, 2018.] https://www. romedic.ro/efectele-fumatului-asupraimplantului-dentar-OP12496

3. Cristache CM, Sfeatcu RI. Mentenanța implanturilor dentare - Cheia succesului pe termen lung a terapiei implanto-protetice. București: Editura CERMAPRINT, 2011.

4. Burlibașa M, Cristache CM, Tănase G. Progrese în medicina dentară, Vol. II. București: Editura Ars Docendi, 2012.

5. Gănuță N, Bucur A, Gănuță A. Tratat de implantologie orală. Bucureșit: Editura National, 1998.

6. Mihai A, Carabela M, Olteanu I et al. Implantele endoosoase osteointegrate în stomatologie. București: Editura Sylvi, 1995.
7. Burlibașa L, Zarnescu O. In vivo effects of Trichostatin A - A histone deacetylase inhibitor - On chromatin remodeling during Triturus cristatus spermatogenesis. Animal reproduction science. 2013, 142 (1-2), 89-99.

8. Gavrila L, Mircea L. Chromatin and chromosomal fine structure in spermatogenesis of some species of amphibians. Zygote. 2001, 9(3), 183-192.

9. Ștețiu AA, Oleksik M, Oleksik V et al. Mechanical behavior of composite materials for dental obturations. Romanian Biotechnological Letters. 2013, 18(4), p. 8528-8538.

10. Bodnar DC, Pantea M, Bodnar T et al. Patologia mucoasei orale la pacienţii vârstnici-studiu clinico-statistic. Acta Medica Transilvanica. 2012, 2(2), p. 56-60.

11. Cristache $C M$, Burlibașa M, Cristache $G$ et al. Zirconia and its biomedical applications. Metalurgia International. 2011, 16(7), 18, p. 18-23.

12. Bodnar DC, Dimova C, Bodnar T et al. Dental management of patient with psychiatric disorders. Modern Medicine. 2010, 17(10), p. 538-543.

13. Lazăr V, Chifiriuc $C$, Bucur $M$ et al. Investigation of dental-plaque formers biofilms by optic and confocal laser scanning microscopy and microbiological tool. Revista Medico-Chirurgicală a Societății de Medici și Naturaliști din lași. 2008, Vol. 112, No. 3, p. 812-820.

14. Burlibașa M, Muntianu LAS, Tănase $G$ et al. Study on microbial contamination of biomaterials in medical practice. Metalurgia International. 2010, 15, p. 163-166.

15. Burlibașa $M$, Cuculescu $M$, Tănase $G$ et al. Dental alloys of prothetic use $-A$ retrospective of their use in Romania. Metalurgia International. 2009, 14, p. 51-53.

16. Burlibașa L, Gavrila L. Developmental epigenetics: roles in embryonic development, In: Niculescu MD, Haggarty P.: Nutrition in Epigenetics, Hoboken, New Jersey: Willey-Blackwell Publishing, 2011, Ch. 6, p. 105-126. 